\title{
Cognitive-Motor Intervention in Alzheimer's Disease: Long-Term Results from the Maria Wolff Trial
}

\author{
Ruben Muñiz ${ }^{\mathrm{a}, *}$, Cristina Massegú Serra ${ }^{\mathrm{a}}$, Barry Reisberg ${ }^{\mathrm{a}, \mathrm{b}}$, José Manuel Rojo $^{\mathrm{c}}$, Teodoro del Ser ${ }^{\mathrm{a}}$, \\ Jordi Peña Casanova ${ }^{\mathrm{a}, \mathrm{d}}$ and Javier Olazarán ${ }^{\mathrm{a}, \mathrm{e}}$ \\ ${ }^{\mathrm{a}}$ Maria Wolff Foundation, Madrid, Spain \\ ${ }^{\mathrm{b}}$ New York University Langone Medical Center, NY, USA \\ ${ }^{\mathrm{c}}$ Superior Council of Scientific Research, Madrid, Spain \\ ${ }^{\mathrm{d}}$ Hospital del Mar, Barcelona, Spain \\ ${ }^{\mathrm{e}}$ Research Unit, Alzheimer Center Reina Sofia Foundation, Carlos III Institute of Health, Madrid, Spain
}

\begin{abstract}
.
Background: Little is known about the long-term acceptance and effects of cognitive and motor stimulation interventions (CMSI) in Alzheimer's disease (AD).

Objective: To evaluate a replicable CMSI program for mild cognitive impairment (MCI) and mild-to-moderate AD persons. Methods: Eighty-four non-institutionalized subjects with AD were randomized to receive either CMSI, administered by a single care provider, or standard support. Cognition, activities of daily living (ADL), mood, and study partner's subjective burden were assessed by blinded raters. Data on institutionalization, psychiatric medications, and demise were collected by the study physicians. Random effects model and survival analyses were conducted, after 2 and 3 years of study.

Results: Three-year assessments could be performed by the physician in $85 \%$ and by the blinded rater in $66 \%$ of subjects. Significant benefits were observed in basic ADL at the 2- and 3-year assessments, whereas instrumental ADL showed benefits only up to the second year of intervention $(p<0.05)$.

Conclusion: Long-term cognitive-motor stimulation is well accepted and produces functional benefits in subjects with AD, with no extra subjective burden in the partner.
\end{abstract}

Keywords: Alzheimer's disease, cognitive stimulation, cognitive-motor stimulation intervention, long-term effects, nonpharmacological therapies, randomized controlled trial

\section{INTRODUCTION}

Cognitive and motor stimulation interventions (CMSI) are provided to patients with Alzheimer's disease (AD) based on the assumption that cognition, function, and mood domains, as well as disease milestones, such as institutionalization, can be positively influenced. These assumptions are supported

*Correspondence to: Ruben Muñiz, Maria Wolff Foundation, Río Sil 15bis, 28660 Boadilla del Monte, Madrid, Spain. Tel.: +34 916322 507; Fax: +34 912663 178; E-mail: ruben@mariawolff.es. by several randomized controlled trials $(\mathrm{RCT})$ that have found positive effects after short-term CMSI for persons with mild to moderate AD [1-3]. The more components these CMSI include, the greater the number of domains that show improvement [4-8]. As a result of this corpus of data, and also supported by the experience and views of the affected individuals, wide societal consensus has been reached that CMSI programs should be offered as one of the essential components of care during the mild-to-moderate stages of AD $[9,10]$. 
While short-term CMSI are clearly beneficial, the long-term feasibility of these interventions and the duration of benefits remain unknown. In most studies, the intervention was performed for short periods of time (usually less than six months) [1-3] and the reports of long-term maintenance of the effects are very scarce $[4,11,12]$. Since $\mathrm{AD}$ is a slowly progressive disease, with the mild and moderate stages together lasting on average 3-4 years [13] and considering the fact that most $\mathrm{AD}$ persons survive into the more advanced stages of disease, the question of how long CMSI benefits may last is of great relevance in terms of quality of life of the affected persons and the total personal and societal cost of the disease.

We conducted a RCT of a cognitive-motor stimulation program for mild cognitive impairment (MCI) and mild-to-moderate AD persons. Benefits in cognition, mood, behavior, and quality of life were reported after one year of treatment [6]. In the present study, we examined the acceptance and efficacy of the cognitivemotor stimulation program, in both subjects and study partners, after a two-year extension period of this trial conducted in two day care centers of the Maria Wolff Foundation in Madrid, Spain.

\section{METHODS}

Details of the methods of the Maria Wolff trial have been described elsewhere [6]. A description following the CONSORT extension guidelines for the report of methods of trials of non-pharmacological interventions [14] is provided in Table 1.

\section{Subjects and study partners}

Subjects were referred to the study secretary from January 1999 to June 2001 by dementia-experienced physicians from 17 outpatient clinical units in the city of Madrid. The inclusion criteria were: a) a clinical diagnosis of either MCI [15] or probable AD [16]; b) Global Deterioration Scale stages 3, 4, or 5 [17]; c) stable and well tolerated dose of a cholinesterase inhibitor; d) acceptance of an eventual stimulation program; e) a study partner willing and able to participate in the study, and f) informed consent signed by the subject and the study partner. Exclusion criteria were illiteracy and any physical condition that could preclude regular attendance and full participation in the intervention program.

Table 1

Consort-type description of the Maria Wolff trial methods

\begin{tabular}{|c|c|}
\hline Item & Description \\
\hline Eligibility criteria & Non-institutionalized person with MCI or probable AD and study partner \\
\hline $\begin{array}{l}\text { Centers performing the } \\
\text { intervention }\end{array}$ & $\begin{array}{l}\text { Single care provider with } 5 \text {-year experience in the design and deliverance of cognitive-motor } \\
\text { stimulation programs for people with AD. The intervention was evenly conducted in two } \\
\text { day care centers. Only experienced therapists were permitted to manage patients in the trial }\end{array}$ \\
\hline $\begin{array}{l}\text { Description of the } \\
\text { intervention, } \\
\text { standardization, and } \\
\text { adherence with the protocol }\end{array}$ & $\begin{array}{l}\text { Cognitive-motor stimulation program consisted of } 3.5 \text { hour sessions, twice weekly, provided } \\
\text { by one therapist (see the text for more details). A manual was created with } 103 \text { sessions for } \\
\text { the first year of intervention. Occasionally, sessions were monitored by members of the } \\
\text { research team and feedback was given to therapists to promote the best possible cognitive } \\
\text { performance from participants, along with a positive affective status. As a result, the } \\
\text { manual of sessions was modified during the three years of intervention. The final version is } \\
\text { available at http://www.mariawolff.org ("Programa Animus"). }\end{array}$ \\
\hline Sample size & $\begin{array}{l}\text { A sample size of } 172 \text { patients ( } 86 \text { in each treatment arm) was estimated to detect a four-point } \\
\text { mean difference in ADAS-cog for a type I error }=0.05 \text {, an } 80 \% \text { power, and a } 20 \% \text { estimated } \\
\text { attrition rate }\end{array}$ \\
\hline Group allocation & $\begin{array}{l}\text { Participants were randomly allocated to the EG or CG with expected proportion } 1: 1 \text { using a } \\
\text { table of random numbers, by a member of the research team who had not access to any data } \\
\text { or information from participants }\end{array}$ \\
\hline Blinding procedures & $\begin{array}{l}\text { Cognition, ADL, mood, and subjective burden were assessed by blinded psychologists, which } \\
\text { were not informed of any aspect of the study design. Blinded assessments were conducted } \\
\text { in a Senior Citizen Center, without any link to the Maria Wolff centers. The participants } \\
\text { were instructed not to make any study-related question or comments to the psychologists }\end{array}$ \\
\hline Statistical methods & $\begin{array}{l}\text { The primary sample for evaluation of efficacy was a MITT sample defined as all randomized } \\
\text { patients who provided at least one post-baseline efficacy assessment and, if they belonged } \\
\text { to the EG, attended at least one session. The evolution of the continuous outcome variables } \\
\text { in the two study groups was compared using random effects model and the evolution of the } \\
\text { categorical outcomes was compared using survival analysis (see the text for more details) }\end{array}$ \\
\hline
\end{tabular}

AD, Alzheimer's disease; ADAS-cog, cognitive subscale of the Alzheimer's Disease Assessment Scale; ADL, activities of daily living; CG, control group; EG, experimental group; MCI, mild cognitive impairment; MITT, modified intent-to-treat. 


\section{Study design and intervention}

After baseline assessment, subjects were randomized to either the experimental (EG) or the control (CG) group in a 1:1 proportion by means of a list of random numbers that was managed by an independent investigator. Subjects assigned to the EG were offered a program of 3.5-h cognitive-motor stimulation sessions, twice weekly. Groups of 7 to 15 individuals were created according to severity of impairment and personal affinities. A comprehensive and uniform stimulation program was designed in accordance with the principles of compensation, with cognition as a primary target. One of a set of six cognitive functions (i.e., attention, language, memory, visuospatial ability, frontal/executive functions, and numerical capacity) was focused in each session and there was a topic which served to motivate the participants and to unify all the sessions of each month one (e.g., the winter in January, the mass media in February, etc.). Efforts were made to elicit the best individual performance within a flexible framework. Sessions were divided into: welcome $(10 \mathrm{~min})$, orientation $(50 \mathrm{~min})$, individual cognitive exercises $(10 \mathrm{~min})$, group cognitive exercises (20 min), ADL training (which was related to the day specific cognitive function) (30 min), coffee break (30 min), psychomotor therapy or workshops (50 min), and conclusion (10 min). A modified internet adaptation and update of this intervention is freely available as "Programa Animus" at http://www.mariawolff.org. Subjects from the EG had to pay a monthly fee of 60 Euro. Subjects from both the EG and the CG received written materials about $\mathrm{AD}$ at the beginning of the study and were also invited to make use of a helpline by calling the study secretary (an experienced social worker).

\section{Efficacy measures}

Efficacy measures were collected at baseline assessment and after 1, 3, 6, 12, 18, 24, and 36 months. The following variables were collected by blinded raters (psychologists):

- Cognitive subscale of the Alzheimer's Disease Assessment Scale (ADAS-cog) [18]. This was the primary efficacy measure. This scale assesses memory, language, ideational praxis, and visuospatial ability with a score range from 0 (best cognitive performance) to 70 (worst cognitive performance).
- Functional Activities Questionnaire (FAQ) [19]. This questionnaire is administered to the caregiver and measures instrumental ADL, with a score range from 0 (total independence in the ADL) to 33 (total dependency).

- Index of ADL [20]. This instrument was administered to the caregiver. It measures daily performance in six basic ADL areas. A score from 0 to 6 , indicating the number of preserved ADL areas, was utilized.

- Geriatric Depression Scale (GDS). The GDS is administered directly to the patient by the rater to evaluate his/her affective status. A 15-item abridged version was utilized [21], with a score range from 0 (no depressive symptoms) to 15 (maximal depressive symptoms).

- Burden Interview (BI). This questionnaire evaluates the subjective burden of the caregiver [22]. A 22-item Spanish version was utilized, with a score range from 0 (no subjective burden) to 88 (maximal burden).

Medications for behavioral and psychological symptoms of dementia (BPSD), attendance at a day-care center, institutionalization, and demise information (subject) as well as medications for psychiatric symptoms (study partner) were collected by the study physicians, who were not blinded to the subject's assigned group status. In case that subjects could not attend the study visit, physicians conducted the visit by telephone.

\section{Statistical analysis}

Descriptive statistics were used to present subject and study partner demographic and clinical characteristics. Differences between subjects and study partners from the two study groups were analyzed at baseline by means of $t$ tests and $\chi^{2}$ tests. The primary sample for evaluation of efficacy was a modified intent-to-treat (MITT) sample defined as all the randomized patients who provided at least one postbaseline efficacy assessment and, if they belonged to the EG, attended at least one therapy session. The evolution of the continuous outcome variables in the two study groups was compared using random effects model, which was adjusted for subject's age, gender, and education (subject outcomes, i.e., ADAS-cog, Index of ADL, FAQ, and GDS) or for study partner's age, gender, education, and cohabitation with subject (study partner outcome, i.e., BI). Change from baseline was chosen as the dependent variable and separate 
regression models were elaborated taking either the 2 - or the 3-year visit as the last observation. The evolution of the categorical outcomes (medications for BPSD, attendance at a day-care center, institutionalization, demise, and medications for study partner psychiatric symptoms) in the two study groups was compared by means of survival analyses, which were also adjusted. The level for statistical significance was set at $p<0.05$ (two-tailed, uncorrected for multiple comparisons). Statistical analyses were performed using SPSS version 16.0 software (SPSS, Chicago, IL, USA) and STATA V12 (StataCorp, College Station, TX, USA).

\section{RESULTS}

A total of 97 were assessed but 13 subjects were not included in the study for different reasons (Fig. 1). Hence, 84 subjects were randomized (44 subjects allocated to the EG and 40 subjects allocated to the CG). Since three subjects rejected enrollment for therapy sessions and one subject could not start the stimulation program because of incident myeloma, the modified intent-to-treat sample included 80 subjects. There were no differences between the EG and the CG participants at study inception in demographic or medical characteristics of subjects and study partners, or in subjects' disease stage and duration (Table 2). All the MCI subjects progressed to fully developed AD dementia during the study period. Physician assessment was

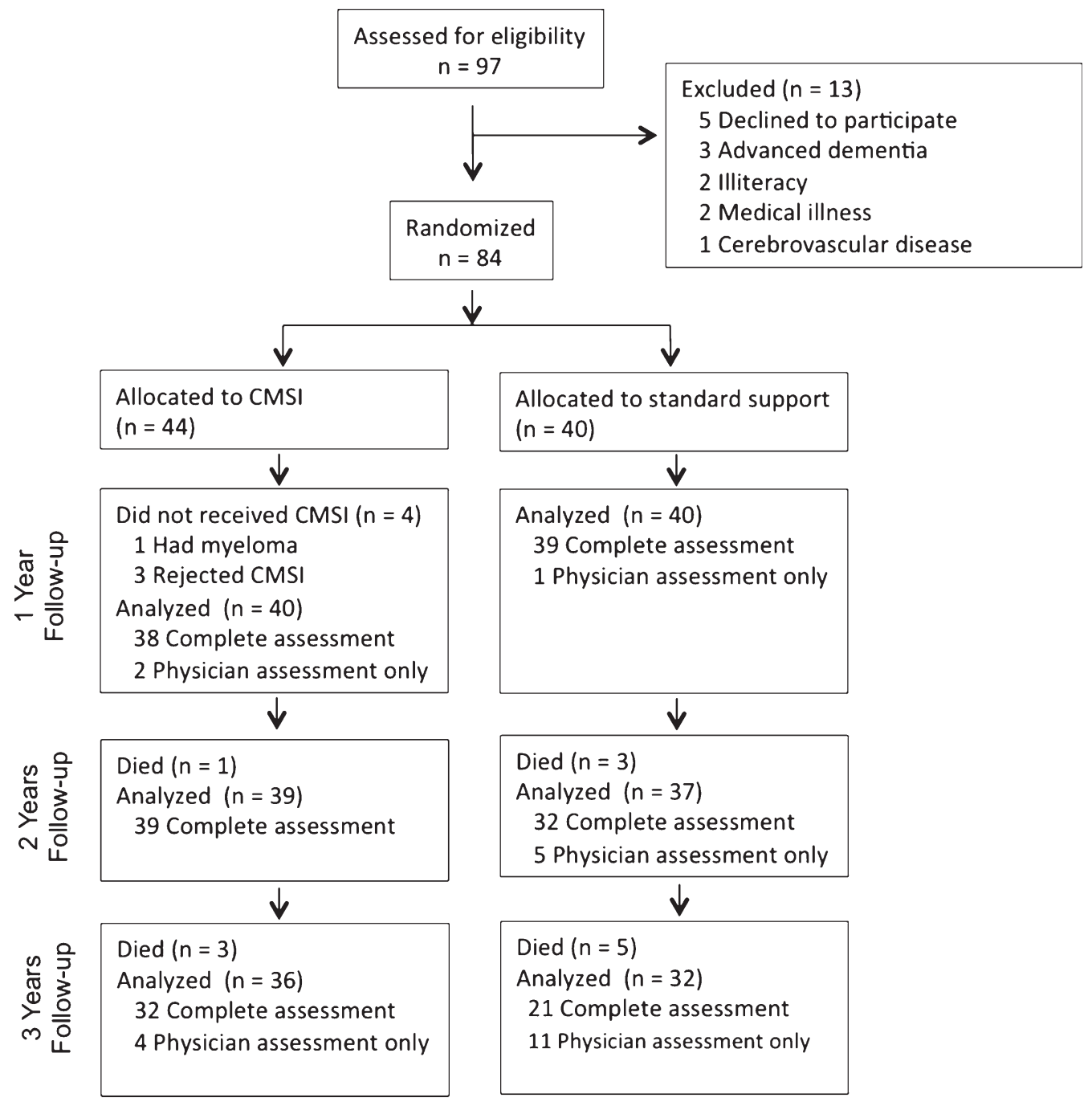

Fig. 1. CONSORT flow diagram of the study. CMSI, cognitive-motor stimulation intervention. 
Table 2

Baseline demographic and clinical characteristics of the study groups

\begin{tabular}{|c|c|c|c|}
\hline Characteristics & $\mathrm{EG}(n=40)$ & $\mathrm{CG}(n=40)$ & $p^{3}$ \\
\hline \multicolumn{4}{|l|}{ Subjects } \\
\hline Mean age, y & $74.9 \pm 1.1(58-87)$ & $73.4 \pm 1.0(54-84)$ & NS \\
\hline Gender ( $\%$ female $)$ & 57.5 & 65.0 & NS \\
\hline Education, $\mathrm{y}$ & $8.1 \pm 0.6(0-18)$ & $7.3 \pm 4.4(0-17)$ & NS \\
\hline Number of chronic illnesses ${ }^{1}$ & $1.1 \pm 0.2(0-4)$ & $1.2 \pm 0.2(0-4)$ & NS \\
\hline Number of medications ${ }^{2}$ & $3.1 \pm 0.2(1-6)$ & $3.3 \pm 0.3(1-9)$ & NS \\
\hline Symptom duration, y & $3.3 \pm 0.4(0.8-16)$ & $3.0 \pm 0.2(0.5-7)$ & NS \\
\hline Global Deterioration Scale (\%) & & & NS \\
\hline Stage 3 & 20.0 & 10.0 & \\
\hline Stage 4 & 52.5 & 60.0 & \\
\hline Stage 5 & 27.5 & 30.0 & \\
\hline MMSE & $17.6 \pm 0.7(8-25)$ & $17.4 \pm 1.0(4-29)$ & NS \\
\hline \multicolumn{4}{|l|}{ Study partners } \\
\hline Mean age, y & $61.0 \pm 2.0(32-81)$ & $57.5 \pm 2.4(29-79)$ & NS \\
\hline Gender ( $\%$ female $)$ & 75.0 & 77.5 & NS \\
\hline Education, y & $10.3 \pm 0.7(3-18)$ & $9.4 \pm 0.6(0-17)$ & NS \\
\hline Number of chronic illnesses & $1.3 \pm 0.2(0-5)$ & $1.1 \pm 0.2(0-4)$ & NS \\
\hline Number of medications & $1.7 \pm 0.3(0-8)$ & $1.3 \pm 0.2(0-5)$ & NS \\
\hline Relationship (\%) & & & NS \\
\hline Spouse & 45.0 & 47.5 & \\
\hline Son or daughter & 42.5 & 42.5 & \\
\hline Other & 12.5 & 10.0 & \\
\hline Living with subject (\%) & 62.5 & 80.0 & NS \\
\hline
\end{tabular}

Values are expressed as mean $\pm \mathrm{SE}$ (range) unless $\%$ is indicated. ${ }^{1}$ Neurologic and psychiatric diseases are not included; ${ }^{2}$ cholinesterase inhibitors and medications for behavioral and psychological symptoms are included; ${ }^{3} p$ values from 2-tailed Student's $t$ test for continuous variables or $\chi^{2}$ test for categorical variables. MMSE, Mini-Mental State Examination; EG, experimental group; CG, control group; NS, statistically not significant $(p>0.05)$.

performed for all of the living subjects at all the study visits during the 3-year study period, whereas the proportion of living subjects who were evaluated by blinded raters at 1-, 2-, and 3-year assessments was, respectively, $96.3 \%, 93.4 \%$, and $77.9 \%$. The rate of CMSI abandon was $25 \%$ each year, including in that figure abandons due to demise. At the end of the three years of intervention, 10 out of 36 living subjects allocated to CMSI were still attending sessions (27.8\%).

The evolution of the efficacy measures in the two study groups is shown in Tables 3 and 4 and a general view of the results in the regression analyses is given in Table 5. Both the EG and the CG showed progressive deterioration in cognitive and functional variables, and in study partner subjective burden $(p<0.05$ at 2 - and 3year analyses), whereas subject affective status slightly improved throughout the study period ( $p<0.05$ at 2and 3-year analyses). A group by time effect was found for the evolution in basic and instrumental ADL, which was favorable for the EG. The effect was obtained in both 2- and 3-year analyses for the Index of ADL, but only in the 2-year analysis for the FAQ (Table 5 and Fig. 2). Since the study by group regression coefficient represents the monthly cumulative difference between the EG and the CG in the dependent variable, the obtained results correspond to a difference of 2.64

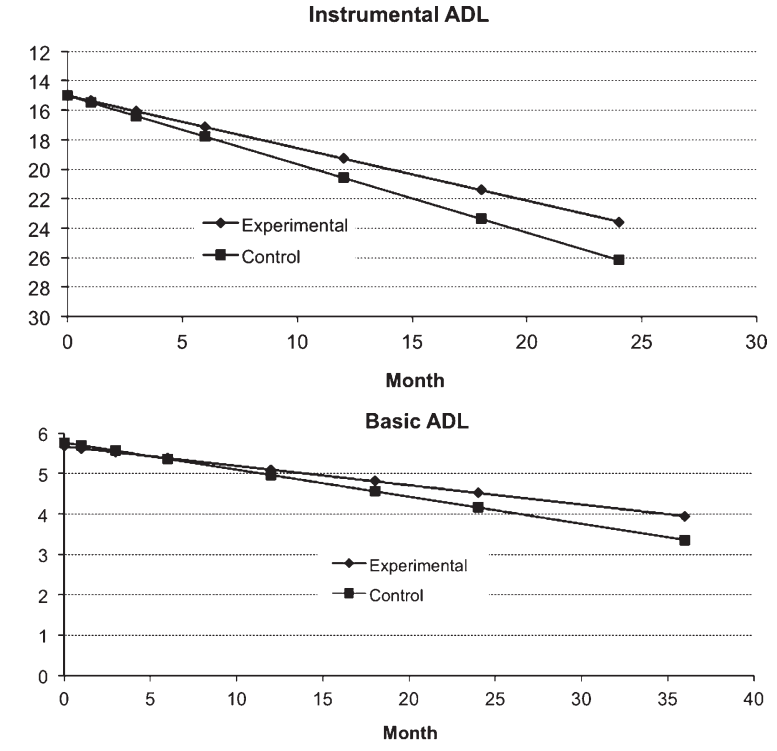

Fig. 2. Modelized evolution of the instrumental ADL (FAQ) (2-year analysis, up) and of the basic ADL (Index of ADL) (3-year analysis, down) in both study groups. More rapid deterioration is observed in the control group $(p<0.05)$. ADL, activities of daily living; FAQ, Functional Activities Questionnaire. 
Table 3

Results in the continuous outcome variables

\begin{tabular}{|c|c|c|c|c|c|c|c|c|}
\hline & & $1 \mathrm{~m}$ & $3 \mathrm{~m}$ & $6 \mathrm{~m}$ & $12 \mathrm{~m}$ & $18 \mathrm{~m}$ & $24 \mathrm{~m}$ & $36 \mathrm{~m}$ \\
\hline \multirow[t]{2}{*}{ ADAS-cog } & EG & $-1.42 \pm 0.7$ & $0.03 \pm 1.97$ & $0.11 \pm 1.02$ & $4.00 \pm 1.28$ & $7.59 \pm 1.62$ & $12.46 \pm 2.25$ & $16.00 \pm 3.21^{*}$ \\
\hline & CG & $0.00 \pm 0.64$ & $0.44 \pm 0.78$ & $1.80 \pm 0.70$ & $6.16 \pm 1.55$ & $9.74 \pm 1.91$ & $12.69 \pm 2.41$ & $12.83 \pm 3.39^{*}$ \\
\hline \multirow[t]{2}{*}{ FAQ } & EG & $-0.84 \pm 0.85$ & $1.91 \pm 0.82$ & $2.58 \pm 0.83$ & $4.58 \pm 0.89$ & $6.34 \pm 1.10$ & $8.47 \pm 1.14^{* *}$ & $13.74 \pm 1.23$ \\
\hline & CG & $-0.09 \pm 0.77$ & $1.37 \pm 0.84$ & $4.47 \pm 0.96$ & $6.72 \pm 0.95$ & $8.38 \pm 1.37$ & $10.90 \pm 1.12^{* *}$ & $13.19 \pm 1.44$ \\
\hline \multirow[t]{2}{*}{ Index of ADL } & EG & $0.19 \pm 0.09$ & $0.00 \pm 0.13$ & $-0.05 \pm 0.15$ & $-0.39 \pm 0.15$ & $-0.49 \pm 0.18$ & $-0.97 \pm 0.22^{*}$ & $-1.84 \pm 0.35^{*}$ \\
\hline & CG & $-0.03 \pm 0.06$ & $-0.19 \pm 0.08$ & $-0.27 \pm 0.08$ & $-0.79 \pm 0.26$ & $-1.11 \pm 0.28$ & $-1.59 \pm 0.36^{*}$ & $-2.33 \pm 0.51^{*}$ \\
\hline \multirow[t]{2}{*}{ GDS } & EG & $-0.09 \pm 0.39$ & $-0.06 \pm 0.38$ & $-0.14 \pm 0.37$ & $-0.38 \pm 0.33$ & $-0.23 \pm 0.48$ & $-1.24 \pm 0.38$ & $-1.10 \pm 0.55$ \\
\hline & CG & $0.03 \pm 0.34$ & $-0.50 \pm 0.37$ & $-0.51 \pm 0.38$ & $0.28 \pm 0.43$ & $-0.33 \pm 0.42$ & $-0.50 \pm 0.73$ & $-0.80 \pm 0.55$ \\
\hline \multirow[t]{2}{*}{ BI } & EG & $-1.40 \pm 1.73$ & $0.81 \pm 1.34$ & $0.35 \pm 1.43$ & $3.12 \pm 1.76$ & $3.43 \pm 2.47$ & $4.74 \pm 1.73$ & $6.35 \pm 3.25$ \\
\hline & CG & $-0.94 \pm 1.41$ & $-0.47 \pm 1.29$ & $1.69 \pm 1.31$ & $4.14 \pm 1.72$ & $3.53 \pm 2.17$ & $9.92 \pm 2.94$ & $4.79 \pm 2.74$ \\
\hline
\end{tabular}

The figures represent the mean $( \pm \mathrm{SE})$ change from baseline in the study outcomes across the study visits. ${ }^{*} p<0.05 ;{ }^{* *} p<0.005$ (regression analysis, group by time effect). ADAS-cog, cognitive subscale of the Alzheimer's Disease Assessment Scale; FAQ, Functional Activities Questionnaire; ADL, Activities of Daily Living; GDS, Geriatric Depression Scale; BI, Burden Interview; EG, experimental group; CG, control group; m, month.

Table 4

Results in the categorical outcomes

\begin{tabular}{|c|c|c|c|c|c|c|c|c|c|}
\hline & & Baseline & $1 \mathrm{~m}$ & $3 \mathrm{~m}$ & $6 \mathrm{~m}$ & $12 \mathrm{~m}$ & $18 \mathrm{~m}$ & $24 \mathrm{~m}$ & $36 \mathrm{~m}$ \\
\hline$n$ & EG & 40 & 40 & 40 & 40 & 40 & 39 & 39 & 36 \\
\hline$n$ & CG & 40 & 40 & 40 & 40 & 40 & 39 & 37 & 32 \\
\hline Medications & EG & 40.0 & 35.1 & 38.5 & 43.6 & 40.0 & 42.1 & 46.2 & 52.8 \\
\hline for BPSD & $\mathrm{CG}$ & 47.5 & 51.4 & 54.1 & 59.0 & 61.5 & 61.5 & 54.1 & 58.1 \\
\hline \multirow[t]{2}{*}{ Day-care center } & EG & 0 & 0 & 0 & 0 & 2.5 & 5.1 & 7.7 & 22.2 \\
\hline & $\mathrm{CG}$ & 0 & 0 & 0 & 0 & 5.0 & 7.7 & 13.5 & 18.8 \\
\hline \multirow[t]{2}{*}{ Nursing home } & EG & 0 & 0 & 0 & 0 & 0 & 2.6 & 10.3 & 22.2 \\
\hline & CG & 0 & 0 & 0 & 2.5 & 10.0 & 10.3 & 18.9 & 25.0 \\
\hline \multirow[t]{2}{*}{ Death } & EG & 0 & 0 & 0 & 0 & 0 & 2.5 & 2.5 & 10.0 \\
\hline & CG & 0 & 0 & 0 & 0 & 0 & 2.5 & 7.5 & 20.0 \\
\hline \multirow[t]{2}{*}{ Psychiatric drugs (study partner) } & EG & 20.0 & 16.2 & 15.4 & 17.9 & 15.0 & 13.2 & 20.5 & 23.7 \\
\hline & CG & 25.0 & 21.6 & 23.1 & 30.8 & 28.2 & 26.3 & 30.6 & 29.4 \\
\hline
\end{tabular}

The figures represent the \% of the evaluated subjects fulfilling the study outcome across the study visits. BPSD: behavioral and psychological symptoms of dementia; EG, experimental group; CG, control group; m, month.

Table 5

Overview of the results in the regression analyses

\begin{tabular}{lccrr}
\hline & & Time $\beta($ CI $95 \%)$ & Study group $\beta($ CI 95\%) & Study group $\times$ Time $\beta($ CI 95\%) \\
\hline ADAS-cog & $2 \mathrm{y}$ & $0.541(0.454,0.628)^{* * *}$ & $2.449(-2.571,7.469)$ & $0.006(-0.120,0.132)$ \\
& $3 \mathrm{y}$ & $0.531(0.460,0.603)^{* * *}$ & $2.847(-2.272,7.966)$ & $-0.066(-0.172,0.039)$ \\
FAQ & $2 \mathrm{y}$ & $0.357(0.297,0.417)^{* * *}$ & $-0.352(-3.613,2.909)$ & $0.109(0.022,0.195)^{*}$ \\
& $3 \mathrm{y}$ & $0.378(0.335,0.421)^{* * *}$ & $0.094(-3.051,3.239)$ & $0.034(-0.030,0.098)$ \\
Index of ADL & $2 \mathrm{y}$ & $-0.041(-0.054,-0.028)^{* * *}$ & $-0.001(-0.377,0.374)$ & $-0.027(-0.046,-0.009)^{* *}$ \\
& $3 \mathrm{y}$ & $-0.048(-0.058,-0.038)^{* * *}$ & $-0.045(-0.462,0.371)$ & $-0.019(-0.034,-0.004)^{*}$ \\
GDS & $2 \mathrm{y}$ & $-0.035(-0.061,-0.008)^{*}$ & $0.365(-0.640,1.370)$ & $0.017(-0.023,0.057)$ \\
& $3 \mathrm{y}$ & $-0.029(-0.049,-0.009)^{* *}$ & $0.405(-0.585,1.395)$ & $0.011(-0.019,0.042)$ \\
BI & $2 \mathrm{y}$ & $0.197(0.014,0.379)^{*}$ & $-2.161(-8.263,3.942)$ & $0.089(-0.162,0.341)$ \\
& $3 \mathrm{y}$ & $0.179(0.076,0.283)^{* *}$ & $-1.836(-7.809,4.137)$ & $0.005(-0.152,0.162)$ \\
\hline
\end{tabular}

The dependent variables appear in the first column; 2- and 3-year random effects model was conducted for prediction of change from baseline in the dependent variables; ${ }^{*} p<0.05 ;{ }^{* *} p<0.005 ;{ }^{* * *} p<0.005$. ADAS-cog, cognitive subscale of the Alzheimer's Disease Assessment Scale; FAQ, Functional Activities Questionnaire; ADL, Activities of Daily Living; GDS, Geriatric Depression Scale; BI, Burden Interview; $\beta$, adjusted regression coefficient; $y$, year.

(95\% CI 0.48 to 4.8 ) in the FAQ at 2-year assessment and to a difference of 0.72 (95\% CI 0.00 to 1.08$)$ in the Index of ADL at the end of the study (Fig. 2).

Cognitive stabilization was observed between 2- and 3-year assessments in the subjects of the CG, whereas the subjects of the EG continued deteriorating (Table 3,
Fig. 3). A logarithmical transformation was considered appropriate for the analysis of the ADAS-cog evolution, which demonstrated a significant group by time effect at the 3-year analysis, in this case favorable to the CG (regression coefficient of -0.003 (95\% CI -0.006 to $-0.000, p=0.039$ ). 
Cognitive performance

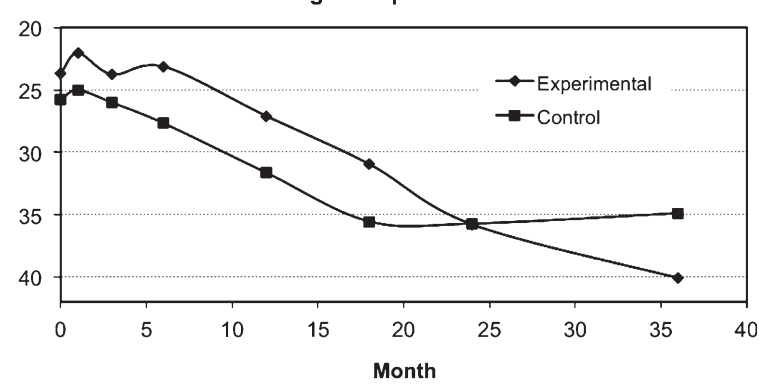

Cognitive performance

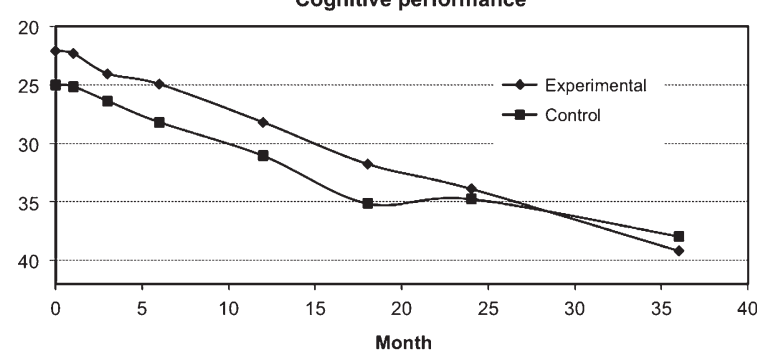

Fig. 3. Raw (up) and adjusted (down) cognitive performance (ADAS-cog) across study visits in both study groups. ADAS-cog, cognitive subscale of the Alzheimer's Disease Assessment Scale.

Table 6

Compliance and satisfaction with the cognitive-motor stimulation program

\begin{tabular}{lrrr}
\hline & $1 \mathrm{y}$ & $2 \mathrm{y}$ & $3 \mathrm{y}$ \\
\hline Subjects attending therapy sessions $(n)$ & 30 & 20 & 10 \\
Subject's score of therapy $(n)$ & & & \\
Very satisfied & 11 & 6 & 3 \\
Satisfied & 14 & 10 & 3 \\
Indifferent & 4 & 2 & 1 \\
Unsatisfied & 0 & 0 & 0 \\
Very unsatisfied & 1 & 0 & 0 \\
Did not answer & 0 & 2 & 3 \\
Study partner's score of therapy $(n)$ & & & \\
Very satisfied & 16 & 8 & 2 \\
Satisfied & 13 & 12 & 8 \\
Indifferent & 1 & 0 & 0 \\
Unsatisfied & 0 & 0 & 0 \\
Very unsatisfied & 0 & 0 & 0 \\
Did not answer & 0 & 0 & 0 \\
\hline
\end{tabular}

The figures represent number of subjects at the end of 1st, 2nd, and 3rd year of intervention. y, year.

The survival analyses of clinical variables and milestones did not display any significant effect (all $p$-values $>0.05$, data not shown). All the evaluations of therapy sessions by the subjects were 'satisfied' or 'very satisfied', after the first and second years of intervention (Table 6). However, at the end of the study, 4 out of 10 subjects did not answer the satisfaction questionnaire (3 subjects) or were indifferent (1 subject).
As for the study partners, they were virtually always satisfied or very satisfied.

\section{DISCUSSION}

We analyzed the effects and long-term acceptance of a program of cognitive and motor stimulation that was offered for three years to persons with MCI, mild or moderate AD, in the context of a RCT. The Maria Wolff trial was unique in the sense that cognitive-motor stimulation was continuously offered and evaluated during a 3-year period and compared against a CG that was offered only standard support. Despite being entitled to individualized help from a social worker specialized in dementia, contacts between the study secretary and the CG were almost always in the context of appointments for the study assessments. Hence, our CG could be considered as a usual care CG. Of note is the observation that a quarter of the subjects allocated to the EG withdrew from the stimulation program every year for different reasons.

This study has resulted in an adequate evaluation of the long-term effects of the cognitive-motor stimulation program on a range of relevant outcomes. There are virtually no studies of long term (i.e., more than one year) effects of cognitive stimulation in $\mathrm{AD}$, alone or as part of a multicomponent intervention. Traditionally, the longest RCT of stimulation programs in AD lasted one year [1-3]. After a comprehensive search by the authors, very few studies could be found which addressed the effects of stimulation programs after more than one year of intervention inception $[4,11$, 12]. In one trial, physical exercise and behavioral problem management was provided during three months and benefits in motor and affective status lasted for two years [4]. In other study, some benefits of a oneyear program of cognitive-motor stimulation and ADL training persisted 10 month after intervention cessation, but authors concluded with the necessity of continuous delivering of therapy to optimize benefits in the long term [12]. Only one trial of cognitive stimulation implemented for more than one year was found. In that trial, $14 \mathrm{AD}$ subjects who received donepezil and cognitive stimulation during 2 years were compared with $20 \mathrm{AD}$ subjects who received donepezil only. Less cognitive deterioration was observed in the subjects who received cognitive stimulation, with no significant effect in mood. However, in that trial, allocation was conducted by registration order, rather than randomization and important outcomes, such as ADL, were not included [11]. 
The present study found clinically relevant effects, which were attributable to the stimulation program. These were observed in: a) a favorable effect of the intervention on basic ADL throughout the entire three year program, b) a favorable effect of the intervention on instrumental ADL only up to the second year, and c) a less clear effect in the cognitive domain, which appeared to improve marginally during the first year of intervention in comparison with the CG; however, the EG performed worse than the CG in terms of the cognitive assessment at the end of the study (Table 3, Figs. 2 and 3). Whereas the observed benefits in ADL are relevant and consistent with a previous study [12], the cognitive results should be cautiously interpreted, in part because of the attrition that was observed at the end of the study, particularly in the CG, which had double the mortality rate of the EG (Fig. 1 and Table 4). Differences in mortality between the two study groups may have produced a false impression of improvement in the $\mathrm{CG}$, due to relatively high performance of the survivors.

The present study had important limitations, mainly derived from an initially underpowered sample size and from the above-mentioned selective attrition in the CG. Less number of participants from the CG received blinded evaluation at 2- and 3-year follow-up assessments due to mortality and missing evaluation, thus raising the possibility of bias. Plausible reasons for lack of blind assessment are lack of motivation and functional deterioration, which is supported by a higher number of institutionalized participants in the CG (Table 4). Hence, it seems unlikely that a selective attrition in the CG fully explains the positive results observed in functional outcomes after 2 and 3 years of intervention. Other limitations of the present study are lack of blindness from participants regarding group allocation and the requirement to pay a small in the participants from the EG, both of which could have produced overestimation of subjects functional capacities by study partners from the EG.

Nevertheless, our overall results are congruent with a model of diminishing responsiveness to therapeutic effort that begins with those domains of last ontogenetic acquisition (cognition) and makes domains of early acquisition (procedural memory, behavior/mood, and motor functions) more responsive to therapeutic intervention during the course of AD [23-25]. The reasons that might explain why cognitive-motor stimulation initially improves cognition and three years later may turn into more deterioration might be manifold, but clearly fall out of the present investigation scope. Stress, sometimes present in subjects undergoing cognitive stimulation, could have con- tributed to a more rapid cognitive deterioration [26, 27] or even we could speculate with some type of accelerating nerve disintegration due to excess of training $[28,29]$ combined with the effect of compromised neurogenesis [30].

The study's results in ADL, which showed significant results up to the second year in instrumental ADL and up to the third year in basic ADL, are encouraging, since systematic ADL training was one of the components of our cognitive-motor stimulation program. Hence, ADL training emerges as a promising target in CMSI, as it may potentially contribute to improve the quality of life of subjects and partners and to reduce the global cost of dementia, beyond the responsiveness of the cognitive domain $[31,32]$. In addition, remarkable trends were observed in all the categorical variables, not reaching statistical significance due to small sample size (Table 4). Larger studies should be conducted to confirm those promising results.

Subjects' satisfaction with the cognitive-motor stimulation program was generally high, but seemed to decrease to some extent in the long term, in parallel with compliance (Table 6). The decrease in subjects' satisfaction with the stimulation program could be explained, at least in part, by lack of memory of sessions (in fact, 2 out of 20 and 3 out 10 subjects did not answer the satisfaction question, respectively, at the 2and 3-year assessments) (Table 6). The appraisal of the program by the study partners was positive across the 3 -year treatment period. That was remarkable, considering the fact that most of the subjects needed some kind of assistance to use means of transportation to attend the bi-weekly sessions, and as a small monetary fee was required for session attendance. Furthermore, no extra subjective burden was observed in the study partners of the EG throughout the entire study period (Tables 3 and 5).

In conclusion, globally considered, the results of a 3-year, multi-component, cognitive-motor stimulation program for persons in the initial stages of $\mathrm{AD}$ were satisfactory for both the subjects and their companions, with benefits on patient function. However, the observed differences in cognitive evolution after three years of intervention raise questions and concerns regarding the long-term adequacy of CMSI in terms of cognition in MCI and AD. Even if our observations with respect to cognition were replicated, it should be noted that functioning, mood, and less behavioral disturbance are probably of considerably greater value to the subjects and their companions, particularly as the $\mathrm{AD}$ process advances, than small gains in terms of cognitive test scores. 


\section{DISCLOSURE STATEMENT}

Authors' disclosures available online (http://j-alz. com/manuscript-disclosures/14-2364r1).

\section{REFERENCES}

[1] Olazarán J, Reisberg B, Clare L, Cruz I, Peña-Casanova J, del Ser T, Woods B, Beck C, Auer S, Lai C, Spector A, Fazio S, Bond J, Kivipelto M, Brodaty H, Rojo JM, Collins H, Teri L, Mittelman M, Orrell M, Feldman HH, Muñiz R (2010) Non-pharmacological therapies in Alzheimer's disease: A systematic review of efficacy. Dement Geriatr Cogn Disord 30, 161-178.

[2] Law LL, Barnett F, Yau MK, Gray MA (2014) Effects of combined cognitive and exercise interventions on cognition in older adults with and without cognitive impairment: A systematic review. Ageing Res Rev 15, 61-75.

[3] Aguirre E, Woods RT, Spector A, Orrell M (2013) Cognitive stimulation for dementia: A systematic review of the evidence of effectiveness from randomised controlled trials. Ageing Res Rev 12, 253-262.

[4] Teri L, Gibbons LE, McCurry SM, Logsdon RG, Buchner DM, Barlow WE, Kukull WA, LaCroix AZ, McCormick W, Larson EB (2003) Exercise plus behavioral management in patients with Alzheimer disease: A randomized controlled trial. JAMA 290, 2015-2022.

[5] Chapman SB, Weiner MF, Rackley A, Hynan LS, Zientz J (2004) Effects of cognitive-communication stimulation for Alzheimer's disease patients treated with donepezil. J Speech Lang Hear Res 47, 1149-1164.

[6] Olazarán J, Muñiz R, Reisberg B, Peña-Casanova J, del Ser T, Cruz-Jentoft AJ, Serrano P, Navarro E, García de la Rocha ML, Frank A, Galiano M, Fernández-Bullido Y, Serra JA, González-Salvador MT, Sevilla C (2004) Benefits of cognitive-motor intervention in MCI and mild to moderate Alzheimer's disease. Neurology 63, 2348-2353.

[7] Tadaka E, Kanagawa K (2004) A randomized controlled trial of a group care program for community-dwelling elderly people with dementia. Japan J Nurs Sci 1, 19-25.

[8] Graessel E, Stemmer R, Eichenseer B, Pickel S, Donath C, Kornhuber J, Luttenberger K (2011) Non-pharmacological, multicomponent group therapy in patients with degenerative dementia: A 12-month randomized, controlled trial. BMC $\operatorname{Med}$ 9, 129.

[9] National Institute of Health and Clinical Excellence Quick Reference Guide (2006) Dementia. Supporting people with dementia and their carers in health and social care. NICE, London.

[10] Lyketsos CG, Colenda CC, Beck C, Blank K, Doraiswamy MP, Kalunian DA, Yaffe K, Task Force of American Association for Geriatric Psychiatry (2006) Position statement of the American Association for Geriatric Psychiatry regarding principles of care for patients with dementia resulting from Alzheimer disease. Am J Geriatr Psychiatry 14, 561-572.

[11] Requena C, Maestu F, Fernandez A, Ortiz T (2006) Effects of cholinergic drugs and cognitive training on dementia: 2-year follow-up. Dement Geriatr Cogn Disord 22, 339-345.

[12] Luttenberger K, Hofner B, Graessel E (2012) Are the effects of a non-drug multimodal activation therapy of dementia sustainable? Follow-up study 10 months after completion of a randomised controlled trial. BMC Neurol 12, 151 .
[13] Reisberg B, Jamil IA, Khan S, Monteiro I, Torossian C, Ferris S, Sabbagh M, Gauthier S, Auer S, Shulman MB, Kluger A, Franssen E, Wegiel J (2010) Staging dementia. In: Principles and Practice of Geriatric Psychiatry, 3rd edition, Abou-Saleh MT, Katona C, Kumar A, eds. Wiley, New York, pp. 162-169.

[14] Boutron I, Moher D, Altman DG, Schulz KF, Ravaud P, Group CONSORT (2008) Methods and processes of the CONSORT Group: Example of an extension for trials assessing nonpharmacologic treatments. Ann Intern Med 148, 295-309.

[15] Flicker C, Ferris SH, Reisberg B (1991) Mild cognitive impairment in the elderly: Predictors of dementia. Neurology 41, 1006-1009.

[16] McKhann G, Drachman D, Folstein M, Katzman R, Price D, Stadlan EM (1984) Clinical diagnosis of Alzheimer's disease: Report of the NINCDS-ADRDA Work Group under the auspices of Department of Health and Human Services Task Force on Alzheimer's Disease. Neurology 34, 939-944.

[17] Reisberg B, Ferris SH, de Leon MJ, Crook T (1982) The Global Deterioration Scale for assessment of primary degenerative dementia. Am J Psychiatry 139, 1136-1139.

[18] Rosen WG, Mohs RC, Davis KL (1984) A new rating scale for Alzheimer's disease. Am J Psychiatry 141, 1356-1364.

[19] Pfeffer RI, Kurosaki TT, Harrah CH, Chance JM, Filos S (1982) Measurement of functional activities in older adults in the community. J Gerontol 3, 323-329.

[20] Katz S, Ford AB, Moskowitz RW, Jackson BA, Jaffe MW (1963) Studies of illness in the aged. The Index of ADL: A standardized measure of biological and psychosocial function. J Am Med Assoc 185, 914-919.

[21] Burns A, Lawlor B, Craig S (1999) Assessment Scales in Old Age Psychiatry, Martin Dunitz, London.

[22] Zarit SH, Reever KE, Bach-Peterson J (1980) Relatives of the impaired elderly: Correlates of feeling of burden. Gerontologist 20, 649-655.

[23] Reisberg B, Franssen EH, Hasan SM, Monteiro I, Boksay I, Souren LE, Kenowsky S, Auer SR, Elahi S, Kluger A (1999) Retrogenesis: Clinical, physiologic, and pathologic mechanisms in brain aging, Alzheimer's and other dementing processes. Eur Arch Psychiatry Clin Neurosci 24 (Suppl 3), 28-36.

[24] Muñiz R, Olazarán J, Tárraga L, Boada M (2004) Intervenciones no farmacológicas. Med Clin Monograph 5, 82-85.

[25] Rubial-Álvarez S, de Sola S, Machado MC, Sintas E, Böhm P, Sánchez-Benavides G, Langohr K, Muñiz R, Peña-Casanova J (2013) The comparison of cognitive and functional performance in children and Alzheimer's disease supports the retrogenesis model. J Alzheimers Dis 33, 191-203.

[26] Carroll JC, Iba M, Bangasser DA, Valentino RJ, James MJ, Brunden KR, Lee VM, Trojanowski JQ (2011) Chronic stress exacerbates tau pathology, neurodegeneration, and cognitive performance through a corticotropin-releasing factor receptor-dependent mechanism in a transgenic mouse model of tauopathy. J Neurosci 31, 14436-14449.

[27] Rissman RA (2009) Stress-induced tau phosphorylation: Functional neuroplasticity or neuronal vulnerability? J Alzheimers Dis 18, 453-457.

[28] Dalakas MC, Elder G, Hallett M, Ravits J, Baker M, Papadopoulos N, Albrecht P, Sever J (1986) A long-term follow-up study of patients with post-poliomyelitis neuromuscular symptoms. N Eng J Med 314, 959-963.

[29] Jankowsky J, Guilian X, Fromholt D, Gonzales V, Borchelt D (2003) Environmental enrichment exacerbates amyloid plaque formation in a transgenic mouse model of Alzheimer's disease. J Neuropathol Exp Neurol 62, 1220-1227. 
[30] Lazarov O, Marr RA (2010) Neurogenesis and Alzheimer's disease: At the crossroads. Exp Neurol 223, 267-281.

[31] Lindholm C, Gustavsson A, Jönsson L, Wimo A (2013) Costs explained by function rather than diagnosis: Results from the SNAC Nordanstig elderly cohort in Sweden. Int J Geriatr Psychiatry 28, 454-462.
[32] Wimo A, Jönsson L, Bond J, Prince M, Winblad B; Alzheimer Disease International (2013) The worldwide economic impact of dementia 2010. Alzheimers Dement 9, 1-11. 